\title{
Tracking Changes in Natural Organic Matter Character in an Australian Drinking Water Catchment
}

\author{
A. Agostino, S. Moradi, H. Bustamante, L. Hamilton, and G. Leslie
}

\begin{abstract}
Research into the elucidation of Natural Organic Matter (NOM) character in surface waters and the link to NOM removal is concentrated to Europe and North America, with limited research conducted on the vastly differing climatic and ecological conditions of Australia. This study utilizes dissolved organic carbon, rapid resin fractionation, liquid chromatography with organic carbon detection and zeta potential measurement techniques to characterize NOM from a riverine, transitional and lacustrine site of an Australian drinking water catchment. The results are compared to similar American, Canadian and French drinking water sources. The robustness of the characterization techniques as an indicator for NOM treatability can be established through application to surface waters of differing geographical regions. Future studies should aim to concurrently characterize NOM character and treatability across a multitude of surface waters in varying geographical locations.
\end{abstract}

Index Terms-Natural organic matter, characterization, surface water, water treatment.

\section{INTRODUCTION}

Removal of natural organic matter (NOM) is critical to drinking water treatment processes as NOM accounts for water colour, membrane fouling and acts as a precursor for the formation of carcinogenic disinfection by products [1]. The effective removal of NOM is critical for sustainable practices in drinking water treatment, which optimize processes such that safe, high quality drinking water is produced with minimal resource consumption. The aim in applying natural organic matter characterization techniques is to yield information towards the effectiveness of water treatment methodologies in removing NOM from source waters, such that processes can be maintained at optimum operating conditions. The characterization techniques are numerous and quantify NOM based on bulk properties (total organic carbon, nitrogen and ultraviolet absorbance) as well

Manuscript received May 13, 2018; revised July 4, 2018. This research has been financed by the Australian Research Council (LP160100600), Sydney Water Corporation and WaterNSW. A.Agostino acknowledges Water Research Australia Limited for support of this project.

A. Agostino and S. Moradi are with the Microbial Advanced Separation Systems Laboratory (bioMASS Lab) and the UNESCO Centre for Membrane Science and Technology, School of Chemical Engineering, UNSW, Sydney, NSW, 2052, Australia (e-mail: anthony.agostino@student.unsw.edu.au, s.moradi@unsw.edu.au).

H. Bustamante is with Sydney Water Corporation, Parramatta, Sydney, NSW, 2150, Australia

L. Hamilton is with WaterNSW, Parramatta, Sydney, NSW, 2150, Australia.

G. Leslie is with the UNESCO Centre for Membrane Science and Technology, School of Chemical Engineering, UNSW, Sydney, NSW, 2052, Australia (corresponding author: G. Leslie; e-mail: g.leslie@ unsw.edu.au). as physiochemical parameters (molecular weight distribution, surface charge, polarity and reactivity). Sophisticated molecular characterization methods have also gained popularity, which aim to elucidate information on NOM elemental composition and structure utilizing techniques such as mass spectroscopy and nuclear magnetic resonance. The character and concentration of NOM are different from one geographical location to another, due to natural ecosystem differences, hydrological conditions and anthropogenic aquatic and atmospheric inputs [2].

Comparative studies on NOM character similarities and differences across geographical locations and the resulting connection towards NOM treatability have previously been studied. The link between Australian and Norwegian surface water demonstrated NOM with a higher humic basis and higher molecular weight distribution in Norwegian surface waters, when compared with Australian [1]. After treatment both water sources demonstrated similar NOM character, indicating recalcitrant NOM as determined by bulk parameters is attributed to the treatment process rather than NOM source variations. However, disinfection chlorine demand was 55\% higher for Norwegian treated water yet yielded a $54 \%$ decrease in the trihalomethane formation potential compared to Australian samples. It is evident that bulk parameters utilized in this study failed to elucidate the specific differences in NOM character that lead to observed differences in NOM treatability.

A similar comparison between Australian and American surface waters indicate total organic nitrogen was more effectively removed in Australian raw water samples than American. It follows that Australian NOM is concluded to be derived from more allochthonous sources than the American samples [3], hence effecting the response of NOM loading to water treatment processes. Again, the lack of resolution bulk parameters display regarding NOM characterization and the link with NOM treatability in comparative studies is highlighted.

Previous comparative studies measure similar bulk parameters for surface waters and conclude with differing NOM treatment outcomes. Consequently, the application of advanced NOM characterization techniques is required to indicate differences in treatability of surface waters of differing geographical regions and the relation to differences in NOM character. An increased awareness of the differences in how changes in NOM characterization relates towards changes in water treatability can validate the robustness of certain NOM characterization methods towards yielding repeatable conclusions towards NOM removability, independantly of spatial influence. Current studies that link NOM character to water treatability are concentrated to vastly 
differing continental climates of Europe and North America. Comparative NOM characterization across geographical locations would allow literature conducted on NOM of one geographical location to be more suitably analysed, modified and applied to NOM of differing geographical locations.

\section{MATERIALS AND METHODS}

\section{A. Catchment Sampling}

Samples were collected from riverine, transitional and lacustrine sites of a water catchment located on the New South Wales-Central Coast, Australia. Samples were collected in duplicate in $1.25 \mathrm{~L}$ polyethylene terephthalate (PET) bottles at consistent depth profiles. Samples were kept at $4{ }^{\circ} \mathrm{C}$ in cold storage and unexposed to light for delivery and storage. Analysis was conducted within 72 hours of sample arrival.

\section{B. Dissolved Organic Carbon (DOC) Analysis}

DOC was measured using a Total Organic Carbon (TOC-LCSH) analyser (Shimadzu, Japan). Samples were filtered through a $0.45 \mu \mathrm{m}$ PES syringe filter (Merck Millipore, Ireland), with DOC quantified utilizing the difference method (DOC $=$ total carbon - inorganic carbon).

\section{Zeta Potential Analysis}

Triplicate measurements were made in a folded capillary cell (DTS1070, Malvern, UK) in a Zetasizer Nano instrument (Malvern, UK) following a standard zeta potential operating procedure.

\section{Rapid Resin Fractionation (RRF) Analysis}

The RRF method follows the methods described by Chow et al. (2004), which were modified from fractionation schemes developed by Bolto et al. (1999) [4], [5]. Briefly, catchment samples $(400 \mathrm{~mL})$ are filtered through a $0.45 \mu \mathrm{m}$ PES filter (Merck Millipore, Ireland) and acidified with $\mathrm{HCl}$ (1M, pH 2), passed through a column of bed height $10 \mathrm{~cm}$ of Supelite DAX-8 resin (Sigma-Aldrich) with a flowrate of $2 \mathrm{~mL}$ per minute. A sample $(50 \mathrm{~mL})$ of the completed column effluent is taken for DOC analysis, with the remaining effluent passed through a second and third column containing Amberlite XAD-4 resin and Amberlite IRA958 resin (Sigma-Aldrich), at identical bed height and flowrate.

\section{E. Liquid Chromatography with Organic Carbon Detection (LC-OCD) Analysis}

NOM was quantified by molecular weight distribution into five distinct fractions, as denoted by Huber et al. (2011) [6]. Samples were filtered through a $0.45 \mu \mathrm{m}$ PES filter (Merck Millipore, Ireland) and loaded into a proprietary LC-OCD-OND (DOC-LABOR, Germany) instrument, based on a Grantzel thin film reactor. A Toyopearl HW-50S gel filtration column is utilized to induce steric interactions that cause elution of molecular weight fractions. The elution from the column is quantified with three on-line detectors: an organic carbon detector (OCD), ultraviolet absorbance detector (UVD) and organic nitrogen detector (OND). Amphiphilic elution is required from the column for low molecular weight acids, which in undertaken through the addition of a phosphate buffer (28mM, pH 6.6) at a flow rate of $1.1 \mathrm{~mL}$ per minute. A portion of the original sample is bypassed from the column to measure total DOC. The International Humic Substances Society (IHSS) Suwanee river Humic and Fulvic acid standards are utilized as reference materials. Manual integration of the measured chromatographs was performed utilizing ChromCALC commercial software (DOC-LABOR, Germany).

\section{RESULTS AND DISCUSSION}

\section{A. Dissolved Organic Carbon (DOC) and Zeta Potential Analysis}

DOC increased from riverine to lacustrine sites, as indicated by Fig. 1, consistent with observations on American surface waters made by Rosario-Ortiz et al. (2007) [7], and Kraus et al. (2010) [8]. The effect of water retention time on increasing NOM concentration in surface water reservoirs is noted in the Australian context.

Zeta potential decreased from $-12.1 \mathrm{mV}$ in the riverine site to $-24.9 \mathrm{mV}$ in the lacustrine site. Since the maximum NOM removal by coagulation occurs from $+5--10 \mathrm{mV}$, the decline in zeta potential from riverine to lacustrine would lead to NOM increasingly recalcitrant to removal by coagulation [9]. Comparative studies which compare zeta potential results from surface waters of differing geographical locations to common treatment methodologies remain the basis for future studies.

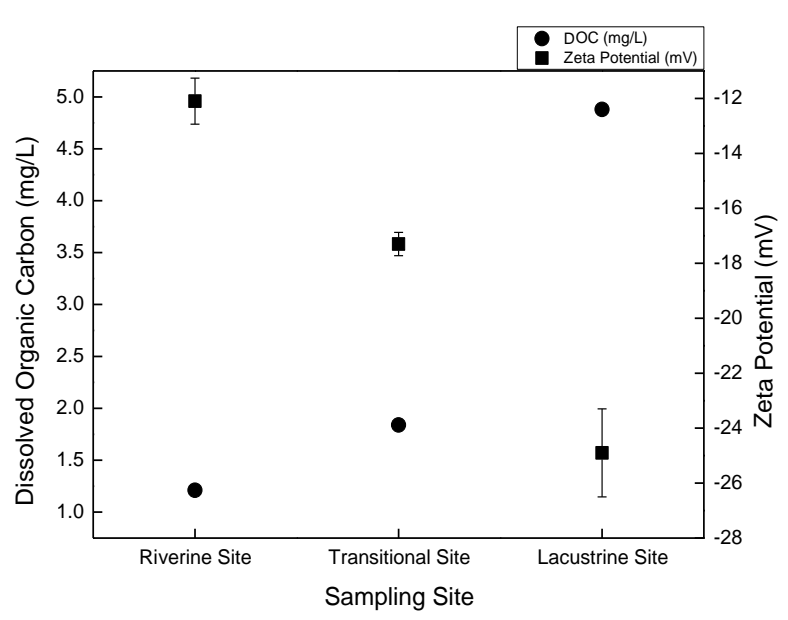

Fig. 1. Dissolved Organic Carbon indicates an increasing trend from riverine to lacustrine sites. Zeta potential decreases from riverine to lacustrine sites.

\section{B. Rapid Resin Fractionation (RRF) Analysis}

An increase in the Slightly Hydrophobic Acid (SHA) and the Very Hydrophobic Acid (VHA) fractions is evident from Transitional to Lacustrine sites, as indicated in Fig. 2. Low initial DOC for the riverine site meant RRF could not be accurately applied for this site. Comparing the Australian lacustrine site to a Canadian lacustrine site analyzed by Sarathy et al. (2010), demonstrates similar NOM character as measured by RRF [10]. The Canadian site had slightly higher \%VHA (66\% compared with $58 \%$ at the Australian Lacustrine site) and a lower \%SHA (17\% compared with $23 \%$ ). Future research should focus on determining if differences in treatment efficiencies exist between these two 
surface waters.

Previous comparative research completed by Fabris et al. has indicated Australian surface waters to have an increasingly variable \%VHA fraction when compared to Norwegian surface waters. This would indicate an increased requirement for Australian sources and treatment processes to be monitored more frequently then compared with Norwegian source waters. It was also found that Australian sources contained a higher proportion of hydrophilic NOM and hence contains an increased amount of NOM which is recalcitrant towards coagulation [1].

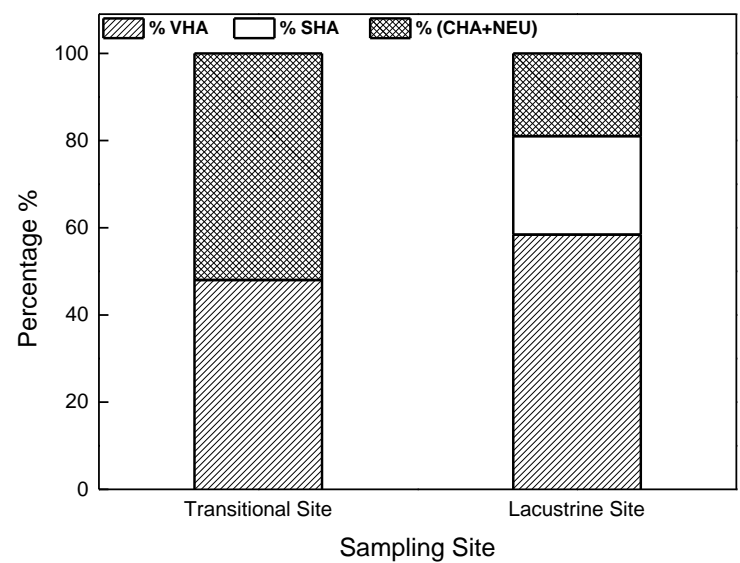

Fig. 2. Rapid Resin Fractionation indicating percent Very Hydrophobic Acids (VHA), Slightly Hydrophobic Acids (SHA), Hydrophilic Charged (CHA) and Hydrophilic Neutral (NEU). An increase in \%(CHA + NEU) is evident between transitional and lacustrine sites.

\section{Liquid Chromatography with Organic Carbon Detection (LC-OCD) Analysis}

The biopolymer (BP), Humic Substances (HS), Building Blocks (BB) and Low Molecular Weight Neutral (LMWN) constituents of NOM increased in concentration from riverine to lacustrine sites, as indicated by Fig. 3. Low Molecular Weight Acids (LMWA) compounds were not found at any of the sites throughout the catchment (below instrument limit of detection of $0.05 \mathrm{mg} / \mathrm{L}$ ). The riverine site displayed no BP fraction, whilst an increase was observed from transitional and lacustrine sites. The HS fraction was the most dominant fraction in all sites, but only accounted for $35 \%$ and $43 \%$ of DOC in transitional and riverine sites respectively yet represented $66 \%$ of DOC in the lacustrine site. Water retention time in reservoir systems is seen as contributing towards the concentration of humic substances. The BB fraction also increased in concentration from riverine to lacustrine sites but was most heavily represented at the transitional site.

French lacustrine surface waters evaluated by Baghoth et al., had a higher proportion of BP (10\% of DOC compared with $3 \%$ for the Australian lacustrine site), slightly lower HS values $(59 \%$ compared to $65 \%)$, higher $\mathrm{BB}$ values $(16 \%$ compared to $9 \%$ ) and equal LMWN values (16\%) [11]. Hence, Australian NOM is indicatively less degraded through a higher percentage of HS and a contrastingly lower percentage of $\mathrm{BB}$ and BP. Comparative studies which compare LC-OCD results from surface waters of differing geographical locations to common treatment methodologies remain the basis for future work.

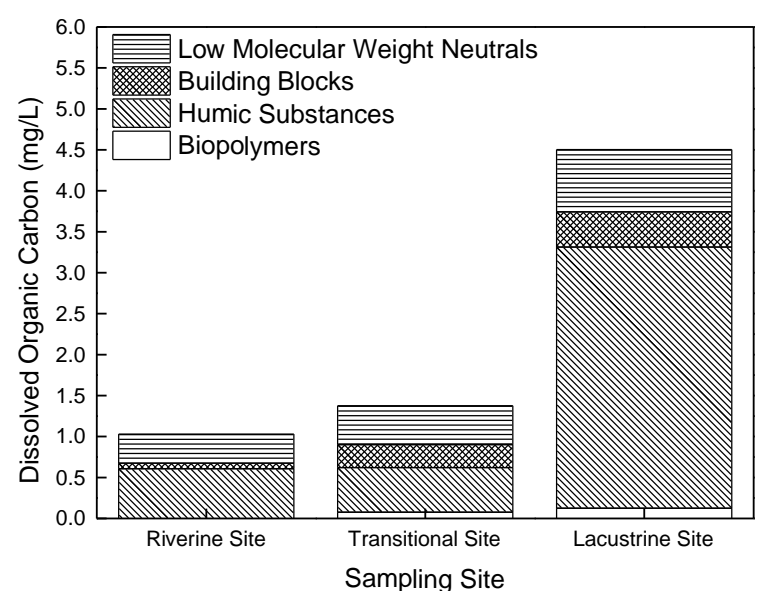

Fig. 3. Liquid chromatography with organic carbon detection indicates an increasing trend in total organic carbon from riverine to lacustrine sites. Biopolymers, building block and low molecular weight neutral components increased from riverine to lacustrine sites.

\section{CONCLUSION}

Changes in NOM character from riverine, transitional and lacustrine sites of an Australian drinking water catchment were tracked in this study. It was shown that water retention time could have an impact on increasing NOM concentration. In addition, a decline in zeta potential from riverine to lacustrine would lead to NOM increasingly recalcitrant to removal by coagulation. The comparison of Australian NOM to other geographical locations has indicated similarities exist in DOC, Zeta potential and RRF trends. However, differences in LC-OCD results were observed. Hence, future studies should aim to simultaneously utilize sophisticated characterization methods in conjunction with NOM removal technologies in a variety of geographical locations, in order to validate the robustness of NOM characterization techniques in drawing conclusions about NOM treatability in a variety of spatial locations. With such research undertaken, the application of literature on NOM removal methodologies can be more suitably applied to geographical locations not captured within original studies.

\section{REFERENCES}

[1] R. Fabris et al., "Comparison of NOM character in selected Australian and Norwegian drinking waters," Water Research, vol. 42, pp. 4188-4196, 2008.

[2] M. A. Zazouli et al., "Study of natural organic matter fractions in water sources of Tehran," Pakistan Journal of Biological Sciences, vol. 10, pp. 1718-1722, 2007.

[3] B. A. Lyon et al., "Organic matter removal and disinfection byproduct management in South East Queensland's s drinking water," Water Science \& Technology: Water Supply, vol. 14, pp. 681-689, 2014.

[4] C. W. K. Chow et al., "A rapid fractionation technique to characterise natural organic matter for the optimisation of water treatment processes," Journal of Water Supply: Research and Technology, vol 53, pp. 85-92, 2004.

[5] B. Bolto et al., "Experimental evaluation of cationic polyelectrolytes for removing natural organic matter from water," Water Science \& Technology: Water Supply, vol. 40, pp. 71-79, 1999.

[6] S. A. Huber et al., "Characterisation of aquatic humic and non-humic matter with size-exclusion chromatography--organic carbon detection--organic nitrogen detection (LC-OCD-OND)," Water Research, vol. 45, pp. 879-885, 2011.

[7] F. L. Rosario-Ortiz et al., "Characterization of the polarity of natural organic matter under ambient condtions by the polarity rapid assessment method (PRAM)," Environmental Science Technology, vol. 41, pp. 4895-4900, 2007. 
[8] T. E. Kraus et al., "Determining sources of dissolved organic carbon and disinfection byproduct precursors to the McKenzie River, Oregon," Journal of Environmental Quality, vol. 39, pp. 2100-2112, 2010.

[9] E. L. Sharp et al., "Coagulation of NOM: Linking character to treatment," Environmental Science \& Technology, vol. 40, pp. 3934-3940, 2010,

[10] S. Sarathy and M. Mohseni, "Effects of UV/H2O2 advanced oxidation on chemical characteristics and chlorine reactivity of surface water natural organic matter," Water Research, vol. 44, pp. 4087-4096, 2010.

[11] S. A. Baghoth et al., "Removal of NOM-constituents as characterized by LC-OCD and F-EEM during drinking water treatment," Journal of Water Supply: Research and Technology, vol. 60, pp. 412-424, 2011.

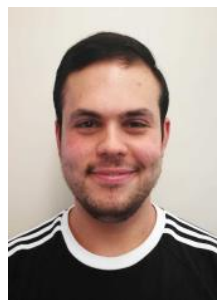

A. Agostino is currently a Ph.D candidate in the School of Chemical Engineering, Faculty of Engineering, University of New South Wales. He received a B.Eng (Hons) in industrial chemistry from the University of New South Wales (2017). His major research interests include water treatment processes, specializing in the study of natural organic matter characterization for drinking water sources. Currently his research focus is on adapting catachment monitoring and potable water treatment to climate change.

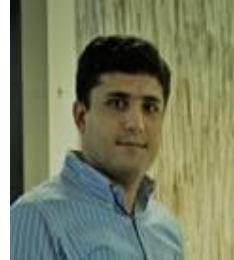

S. Moradi is a postdoctoral research associate in the School of Chemical Engineering, Faculty of Engineering, University of New South Wales. He received a B.Sc. in chemical engineering from Iran University of Science and Technology (2011) and M.Sc. in chemical engineering-process design from Sharif University of Technology (2013). His major research interests are in the areas of water treatment processes and characterization techniques for monitoring of natural organic matter in drinking water. Currently, his research focus is on adapting catchment monitoring and potable water treatment to climate change. He was a graduate researcher in SA Water (Adelaide, Australia) in 2016, where he collaborated with treatment and network planning team, as well as research and innovation services team. 